\title{
The legacy of Jeremy Safran
}

\author{
Vittorio Lingiardi, Daniela Gentile \\ Department of Dynamic and Clinical Psychology, Faculty of Medicine and Psychology, "Sapienza” University of Rome, Rome, Italy
}

One year ago, on the 7th of May, Jeremy Safran passed away. His death left a big hole in our hearts and in our community. In this issue of Research in Psychotherapy: Psychopathology, Process and Outcome, we want to remember him as a friend, scholar, clinician, and researcher.

Jeremy taught psychology at the New School for Social Research in New York, where he co-chaired the Sandor Ferenczi Center and worked as a research director at Beth Israel Medical Center. He was president of the International Association for Relational Psychoanalysis and Psychotherapy and was always an active member of the Society for Psychotherapy Research.

He was also very renowned in Italy, where his books were translated and appreciated for the depth of his clinical suggestions and the methodological rigor of his studies. Two of his books are available to the Italian readership: Teoria e pratica dell'alleanza terapeutica [original book: Negotiating the therapeutic alliance (Safran \& Muran, 2000), Italian translation in 2003] and Psicoanalisi e terapie psicodinamiche [original book: Psychoanalysis and psychoanalytic therapies (Safran, 2012), Italian translation in 2013].

Jeremy's work was characterized by the pluralism of theories and the integration of theory, clinical reflection,

Correspondence: Vittorio Lingiardi, Department of Dynamic and Clinical Psychology, Faculty of Medicine and Psychology, "Sapienza" University of Rome, Via dei Marsi 78, 00185 Rome, Italy.

E-mail: vittorio.lingiardi@uniroma1.it

Key words: Jeremy Safran; Legacy; Psychotherapy research.

Citation: Lingiardi, V., \& Gentile, D. (2019). The legacy of Jeremy Safran. Research in Psychotherapy: Psychopathology, Process and Outcome, 22(1), 1-2. doi: 10.4081/ripppo.2019.388

Received for publication: 16 March 2019.

Accepted for publication: 18 March 2019.

This work is licensed under a Creative Commons Attribution NonCommercial 4.0 License (CC BY-NC 4.0).

(C) Copyright V. Lingiardi, D. Gentile, 2019

Licensee PAGEPress, Italy

Research in Psychotherapy:

Psychopathology, Process and Outcome 2019; 22:1-2

doi:10.4081/ripppo.2019.388 and research. He wrote: "I have never felt comfortable identifying myself exclusively with any one therapeutic tradition and my writing has tended to reflect a predilection for positioning myself on the boundaries between orientations" (Safran, 2003a, p. 450). Indeed, it was true; Jeremy was able to integrate not only different souls (of researcher, theorist, and clinician) but also different therapeutic approaches (cognitivism, interpersonal theories, and relational psychoanalysis). Starting from the long collaboration with Leslie Greenberg in the early eighties, Jeremy never aimed to integrate different theories because of some kind of ideology but as the result of personal, clinical, and conceptual research.

His research on the processes of ruptures and repairs in the therapeutic alliance represents the quintessence of his thinking and of his clinical proposal. He focused on the patients' and therapists' emotional experience, the interpersonal dimension of clinical work, and attention to the here and now in the therapeutic relationship. The therapeutic alliance is not a given, nor an a priori requirement. It is a process of ongoing negotiation that in some cases, for example in the treatment of patients with severe personality disorders, can constitute the purpose of the treatment itself.

The conceptualization of the therapeutic alliance proposed by Jeremy (together with Chris Muran) is empirically based and grounded in task-analytic investigations, a method that allows for the construction of clinical models that describe the different ways in which the alliance breaks down (i.e., withdrawal or confrontation) and the stages that can usually be identified when those are resolved. The meaning of any technical element can therefore be only understood in the relational context in which it emerges, and the technical indications provided by the authors are not standardized manual-type prescriptions but almost "experiences lived in the relational frame" (Safran \& Muran, 2000).

Closer and closer to oriental philosophies and in particular to Buddhism (among his works, we remember the 2003 book Psychoanalysis and Buddhism: An Unfolding Dialogue; Safran, 2003b), Jeremy tried to accept and appreciate things for what they are, not for passivity but to grasp the essence. He said that in approaching the patient, it was necessary to have "the mind of the beginner".

Research in Psychotherapy: Psychopathology, Process and Outcome wants to honor the memory of Safran with a special issue composed of two main sections 
(Issue 1 in April and Issue 2 in July) including theoretical papers, clinical cases, and empirical qualitative and quantitative studies. Although considering different approaches, methodologies, and research designs, all the paper contributions presented share a common focus on ruptures and resolutions of therapeutic alliance.

In the present issue, Adam Horvath's introductive contribution Jeremy Safran: a hero 's journey (Horvath, 2019 pp. 3-6) delineates the deep meaning of Jeremy's legacy and proposes some reflection concerning the clinical implications of his model. Samstag and Muran's (2019 pp. 7-14) theoretical contribution, Ruptures, repairs, and reflections: contributions of Jeremy D. Safran, discusses the centrality of the rupture and resolution process and its role in the patient's change. In their commentary, Jeremy Safran's impact on Italian psychotherapy research and practice: a window into the processes involved in therapeutic alliance, Locati, Del Corno, and Parolin (2019 pp. 15-18) highlight how Safran's work significantly influenced the Italian clinical and research context. In the paper Detecting alliance ruptures: the effects of therapist's experience, attachment, empathy and countertransference management skills, Talbot, Ostiguy-Pion, Painchaud, Lafrance, and Descôteaux (2019 pp. 19-28) explore the effects of some therapists' characteristics (clinical experience, attachment, empathy, countertransference) in their capacity to capture the alliance ruptures.

The paper by Marmarosh et al. (2019 pp. 29-33), Carrying Jeremy Safran into sessions: relying on internal representations of researchers to facilitate emotion regulation, clinical intervention, and self-efficacy underlines Safran's influence on therapists' training and evidences the importance of internalizing the technical strategies to manage the ruptures in the session and to focus on the emotions in the here and now of the relationship. The qualitative research by Morán, Martínez, Varas, and Parra Sepulveda (2019 pp. 34-44), The subjective experience of psychotherapists during moments of rupture in psychotherapy with adolescents, depicts the therapist's perspective when rupture episodes occur in adolescents' treatment. Nof, Dolev, Leibovich, and ZilchaMano (2019 pp. 45-47), in If you believe that breaking is possible, believe also that fixing is possible: a framework for ruptures and repairs in child psychotherapy, propose a model for identifying and repairing ruptures in child psychotherapy based on Safran and Muran's model. The study Linguistic features of the therapeutic alliance in the first session: a psychotherapy process study by Negri et al. (2019 pp. 71-82) examines how some linguistic measures indicative of joint emotional elaboration correlate with the therapeutic alliance assessed within a single session. Last but not least, the paper by Lo Coco, Tasca, Hewitt, Mikail, and Kivlighan, Jr. (2019 pp. 58-70), entitled Ruptures and repairs of group therapy alliance. An untold story in psychotherapy research, highlights the characteristics of ruptures and repairs of group alliance and potential methods and research strategies to analyze group alliance interactions.
Thanks to all the authors who have participated to this special issue, contributing to disseminate the teachings of Jeremy Safran and keep his memory alive.

\section{References}

Horvath, A. O. (2019). Jeremy Safran: a hero's journey. Research in Psychotherapy: Psychopathology, Process and Outcome, 22(1), 3-6.

Lo Coco, G., Tasca, G. A., Hewitt, P. L., Mikail, S. F., \& Kivlighan Jr, D. M. (2019). Ruptures and repairs of group therapy alliance. An untold story in psychotherapy research. Research in Psychotherapy: Psychopathology, Process and Outcome, 22(1), 58-70.

Locati, F., Del Corno, F., \& Parolin, L. (2019). Jeremy Safran's impact on Italian psychotherapy research and practice: a window into the processes involved in therapeutic alliance. Research in Psychotherapy: Psychopathology, Process and Outcome, 22(1), 15-18.

Marmarosh, C. L., Abbatelli, C., Tulipan, M., Kaleka, J., Ohanesian, J., \& Howson, C. (2019). Carrying Jeremy Safran into sessions: relying on internal representations of researchers to facilitate emotion regulation, clinical intervention, and self-efficacy. Research in Psychotherapy: Psychopathology, Process and Outcome, 22(1), 29-33.

Morán, J., Díaz, M. F., Martínez, C., Varas, C., \& Parra Sepulveda, R. (2019). The subjective experience of psychotherapists during moments of rupture in psychotherapy with adolescents. Research in Psychotherapy: Psychopathology, Process and Outcome, 22(1), 34-44.

Negri, A., Christian, C., Mariani, R., Belotti, L., Andreoli, G., \& Danskin, K. (2019). Linguistic features of the therapeutic alliance in the first session: a psychotherapy process study. Research in Psychotherapy: Psychopathology, Process and Outcome, 22(1), 71-82.

Nof, A., Dolev, T., Leibovich, L., Harel, J., \& Zilcha-Mano, S. (2019). If you believe that breaking is possible, believe also that fixing is possible: a framework for ruptures and repairs in child psychotherapy. Research in Psychotherapy: Psychopathology, Process and Outcome, 22(1), 45-57.

Safran, J. D. (2003a). The relational turn, the therapeutic alliance and psychotherapy research: Strange bedfellows or postmodern marriage?. Contemporary Psychoanalysis, 39(3), 449-475.

Safran, J. D. (2003b). Psychoanalysis and buddhism: An unfolding dialogue. Boston: Wisdom Publications.

Safran, J. D. (2012). Psychoanalysis and psychoanalytic therapies. Washington, DC: American Psychological Association. (Tr. it. Psicoanalisi e terapie psicodinamiche. Milano, Cortina; 2013).

Safran, J. D., \& Muran, J. C. (2000). Negotiating the therapeutic alliance. A relational treatment guide. New York: Guilford Press. (Tr. it. Teoria e pratica dell'alleanza terapeutica. Bari: Laterza; 2003).

Samstag, L. W., \& Muran, J. C. (2019). Ruptures, repairs, and reflections: contributions of Jeremy D. Safran. Research in Psychotherapy: Psychopathology, Process and Outcome, 22(1), 7-14.

Talbot, C., Ostiguy-Pion, R., Painchaud, E., Lafrance, C., \& Descôteaux, J. (2019). Detecting alliance ruptures: the effects of therapist's experience, attachment, empathy and countertransference management skills. Research in Psychotherapy: Psychopathology, Process and Outcome, 22(1), 19-28. 